\title{
Identification of a Vulnerable Group for Post-Acute Sequelae of SARS-CoV-2 (PASC): People with Autoimmune Diseases Recover More Slowly from COVID-19
}

\author{
Nancy Dreyer (iD) \\ Natalia Petruski-Ivleva' \\ Lisa Albert' \\ Damir Mohamed ${ }^{2}$ \\ Emma Brinkley' \\ Matthew Reynolds' \\ Stephen Toovey ${ }^{3}$ \\ 'Real World Solutions, IQVIA
}

Cambridge, Cambridge, MA, USA; ${ }^{2}$ Real

World Solutions, IQVIA Courbevoie,

Courbevoie, France; ${ }^{3}$ Pegasus Research,

Bottmingen, Switzerland
Correspondence: Nancy Dreyer

Real World Solutions, IQVIA Cambridge,

20I Broadway, 5th Floor, Cambridge, MA,

02139 , USA

Tel + I 6177339478

Email Nancy.Dreyer@IQVIA.com
Purpose: Evidence is emerging that a significant percentage of COVID-19 cases experience symptom persistence beyond 30 days and go on to develop post-acute sequelae. Our objective was to compare the risk for COVID-19 symptom persistence by self-reported use of medications for autoimmune disease among participants of an on-line COVID-19 registry. Patients and Methods: A community-based online survey collected weekly data on COVID-19 symptom presentation. Participants who completed informed consent online, reported a positive COVID-19 test result within 14 days prior to enrollment and also reported demographics, underlying illnesses, and medication use were included. Symptom presence and severity were evaluated weekly after enrollment and compared between participants reporting use of medications for autoimmune conditions and all others. Logistic regression was used to evaluate the odds of more severe acute illness and symptom persistence approximately 30 days after enrollment.

Results: A total of 1,518 COVID-19-positive participants were included. Participants reporting use of medications for autoimmune disease $(n=70)$ were more likely to have experienced symptoms at all time points over a 30-day time period and were more likely to report more severe presentation of COVID-19 during acute illness (adjusted OR $(95 \% \mathrm{CI})=1.32(0.76-2.29))$ compared to those reporting not taking medications for autoimmune disease. At about 30 days after enrollment, users of medications for autoimmune disease were more than twice as likely to report three or more symptoms (adjusted OR $(95 \% \mathrm{CI})=2.53(1.21-5.29)$ ). In particular, their risk of persistent shortness of breath and fatigue was elevated (adjusted OR $(95 \% \mathrm{CI})=2.66(1.15-6.18)$ and 4.73 (2.17-10.34), respectively).

Conclusion: Individuals with underlying autoimmune conditions appear to be particularly vulnerable to post-acute sequelae from COVID-19; early intervention might be considered. Keywords: COVID-19, PASC, autoimmune, direct-to-patient, fatigue, shortness of breath

\section{Introduction}

Evidence is emerging that a significant percentage, perhaps $50 \%$ or more, of acutely symptomatic COVID-19 cases experience symptom persistence beyond 30 days and go on to develop post-acute sequelae (PASC), often referred to as "Long COVID", a prolonged illness that can interfere with return to normal life. ${ }^{1}$ People with autoimmune conditions may be at higher risk for prolonged disease, although existing reports are inconclusive., ${ }^{2,3}$ We report findings from an online community-based 
registry of patient-reported symptoms for 1,518 adults who had recently tested positive for COVID-19 and who had provided information about their use of medications for autoimmune conditions. ${ }^{4}$

\section{Patients and Methods}

The registry protocol has received institutional review approval and all participants provided informed consent. The protocol is updated periodically and is available on clinicaltrials.gov. Participants are recruited via social media, with many having responded to an enrollment appeal in January, 2021, directed to adults in the US who had tested positive for COVID-19 with any test type (www.helpstopCOVID19.com). Fewer than half of the participants $(45 \%)$ received a modest incentive of up to \$60 USD for daily survey completion during a 30-day period as part of a substudy; only weekly responses are included here.

At enrollment, community-based participants reported demographics, COVID-19 test results, medical history, the presence and severity of COVID-19-like symptoms on a 4-point scale, and use of medications (prescription, nonprescription, and dietary supplements). ${ }^{3,5}$ The cohort used for this analysis were enrolled between April 15, 2020 and March 1, 2021, reported having received a positive COVID-19 test result within the 14 days preceding enrollment, and completed at least one follow-up survey. Symptoms and severity were assessed weekly for 30 days. An overall severity score was calculated as the sum of individual scores $(0=$ absent; $1=$ mild/very mild; $2=$ moderate; $3=$ severe) across 15 symptoms. Participants who responded "yes" to the survey question: "Are you currently taking medications for autoimmune disease (eg, rheumatoid arthritis, ankylosing spondylitis)?" were compared to those who responded "no". Logistic regression was used to estimate the Odds Ratios (OR) and 95\% Confidence Intervals (95\% CI) for experiencing i) more severe COVID-19 presentation at enrollment and ii) symptom persistence over approximately 30 days for those who reported using medications for autoimmune conditions compared to all other participants (ie, referent group). A more severe COVID-19 presentation at study enrollment was defined as reporting the number of COVID-19 symptoms $\geq$ median or having a severity score of $\geq$ median, based on the referent group's distributions of count and score. Based on the distribution of the number of symptoms and severity score in our population, two endpoints were selected to describe a severe presentation of COVID-
19 at enrollment, based on the median value among nonusers of medications for autoimmune conditions: i) a symptom count $\geq 7$; or ii) a severity score of $\geq 11$. Symptom persistence at approximately 30 days was defined as reporting a symptom count $\geq 75$ th percentile of the referent group's distribution. Additionally, the odds of experiencing persistent fatigue and shortness of breath at approximately 30 days were included as outcomes of special interest, as those symptoms are commonly reported as having a significant impact on the ability to perform daily living and work activities; ${ }^{6-9}$ persistent shortness of breath may also indicate long-term damage to the lungs. ${ }^{10}$ Potential confounders included in all models were demographics and risk factors for more severe COVID-19 disease: age in 10-year intervals, gender, race, ethnicity, body mass index (BMI) category, level of education, smoking status, use of medications for diabetes, hypertension, or lung disease. Models for 30-day symptom persistence were additionally adjusted for the number of symptoms reported at enrollment to account for differential reporting patterns (eg, those reporting more symptoms at enrollment might also report more symptoms in follow-up). Some categories were combined, such as for age, race, level of education, to facilitate interpretation of model estimates as well as to avoid categories with small numbers, to maximize model fit. Data collection and study conduct followed all ethical principles outlined in the Declaration of Helsinki for the conduct of medical research.

\section{Results}

Participants who reported testing positive for COVID-19 within the 14 days preceding enrollment $(n=1,518$; median $[\mathrm{IQR}]=7$ [4-9] days) included 70 (4.6\%) individuals who reported taking medication for an autoimmune condition. Participants taking medication for an autoimmune condition were on average older (mean age 46.9 vs 40.9 years), less likely to be Hispanic or Latino ( $7 \%$ vs $16 \%$ ), and more likely to be female ( $93 \%$ vs $87 \%$ ) and to report other comorbidities compared to all other participants (Table 1).

Participants reporting use of medications for autoimmune disease reported a median [IQR] of 7 [5-9] symptoms at enrollment, while the median [IQR] number of symptoms for all other participants was 7 [4-9]. The median [IQR] severity score at enrollment for those reporting use of medications for autoimmune disease was 12 [717] compared to 10 [6-15] for non-users (Table 1). More than $50 \%$ of participants in both groups reported fatigue, headache, nasal congestion, cough, aches and pains, and/or 
Table I Characteristics of COVID-19-Positive CARE Registry Participants at Enrollment by Self-Reported Use of Medications for Autoimmune Disease

\begin{tabular}{|c|c|c|c|c|}
\hline & \multicolumn{2}{|c|}{ Participants at Enrollment } & \multicolumn{2}{|c|}{ Participants with Follow-Up Around Day 30} \\
\hline & $\begin{array}{c}\text { Taking Medications } \\
\text { for Autoimmune } \\
\text { Disease }\end{array}$ & $\begin{array}{c}\text { Not Taking Medications } \\
\text { for Autoimmune } \\
\text { Disease }\end{array}$ & $\begin{array}{c}\text { Taking Medications } \\
\text { for Autoimmune } \\
\text { Disease }\end{array}$ & $\begin{array}{c}\text { Not Taking Medications } \\
\text { for Autoimmune } \\
\text { Disease }\end{array}$ \\
\hline & $(n=70)$ & $(n=I, 448)$ & $(n=4 I)$ & $(n=936)$ \\
\hline $\begin{array}{l}\text { Age, years } \\
\text { Mean (SD) } \\
\text { Median (IQR) }\end{array}$ & $\begin{array}{c}46.9(10.5) \\
45.5(41-54)\end{array}$ & $\begin{array}{l}40.9(11.9) \\
40(32-49)\end{array}$ & $\begin{array}{c}48.6(10.3) \\
48(43-4)\end{array}$ & $\begin{array}{l}4 I .6(11.8) \\
4 I(33-50)\end{array}$ \\
\hline & n (\%) & n (\%) & n (\%) & n (\%) \\
\hline $\begin{array}{l}\text { Gender } \\
\text { Female }\end{array}$ & $65(92.9)$ & $1257(86.8)$ & $39(95.5)$ & $817(87.3)$ \\
\hline $\begin{array}{l}\text { Education } \\
\text { High school or less } \\
\text { Some college/2-year degree } \\
\text { 4-year college degree } \\
\text { >4-year college degree }\end{array}$ & $\begin{array}{l}3(2.86) \\
30(42.8) \\
20(28.6) \\
15(21.4)\end{array}$ & $\begin{array}{l}229(15.8) \\
553(38.2) \\
326(22.5) \\
304(21.0)\end{array}$ & $\begin{array}{c}\text { I }(2.4) \\
15(36.6) \\
14(34.2) \\
10(24.4)\end{array}$ & $\begin{array}{l}139(14.9) \\
338(36.1) \\
233(24.9) \\
213(22.8)\end{array}$ \\
\hline $\begin{array}{l}\text { Race } \\
\text { Black or African American } \\
\text { White } \\
\text { Other }\end{array}$ & $\begin{aligned} 6 & (8.6) \\
58 & (82.9) \\
6 & (8.5)\end{aligned}$ & $\begin{array}{l}85(5.87) \\
\mathrm{I}, 14 \mathrm{I}(78.8) \\
222(5.3)\end{array}$ & $\begin{aligned} & (7.3) \\
36 & (87.8) \\
& \text { I }(2.4)\end{aligned}$ & $\begin{array}{c}54(5.8) \\
765(81.7) \\
117(12.5)\end{array}$ \\
\hline $\begin{array}{l}\text { Ethnicity } \\
\text { Hispanic or Latino }\end{array}$ & $5(7.2)$ & $228(15.8)$ & $5(12.2)$ & $142(15.2)$ \\
\hline $\begin{array}{l}\text { BMI group } \\
\text { Normal }(<25) \\
\text { Overweight }(25-30) \\
\text { Obese }(\geq 30)\end{array}$ & $\begin{array}{l}13(18.6) \\
17(24.3) \\
38(54.3)\end{array}$ & $\begin{array}{l}352(24.3) \\
366(25.3) \\
683(47.7)\end{array}$ & $\begin{array}{l}9(22.0) \\
11(26.8) \\
20(48.5)\end{array}$ & $\begin{array}{l}214(22.9) \\
244(26.1) \\
458(49.0)\end{array}$ \\
\hline $\begin{array}{l}\text { Medical history } \\
\text { Smoker } \\
\text { Cardiovascular Disease } \\
\text { (incl. heart disease, stroke) }\end{array}$ & $\begin{array}{l}\text { I (I.4) } \\
5(7.14)\end{array}$ & $\begin{array}{l}13(0.9) \\
52(3.6)\end{array}$ & $\begin{array}{l}0(0.0) \\
3(7.3)\end{array}$ & $\begin{array}{l}88(9.4) \\
36(3.9)\end{array}$ \\
\hline $\begin{array}{l}\text { Taking Medication for } \\
\text { Diabetes }\end{array}$ & $9(12.9)$ & $93(6.4)$ & $5(12.2)$ & 61 (6.5) \\
\hline $\begin{array}{l}\text { Taking Medication for } \\
\text { Hypertension }\end{array}$ & $21(30.0)$ & $240(16.6)$ & $9(22.0)$ & $144(15.4)$ \\
\hline $\begin{array}{l}\text { Taking Medication for Lung } \\
\text { Disease }\end{array}$ & $10(14.3)$ & $87(6.0)$ & $5(12.2)$ & $62(6.6)$ \\
\hline $\begin{array}{l}\text { Hospitalized Due to Likely } \\
\text { COVID-19 Related } \\
\text { Incentivized }\end{array}$ & $\begin{array}{c}2(2.9) \\
35(50.0)\end{array}$ & $\begin{array}{c}18(1.2) \\
793(54.8)\end{array}$ & $\begin{array}{c}\text { I (2.4) } \\
28(68.3)\end{array}$ & $\begin{array}{c}8(0.9) \\
666(71.2)\end{array}$ \\
\hline $\begin{array}{l}\text { Distribution of Symptoms at } \\
\text { Enrollment }\end{array}$ & & & & \\
\hline $\begin{array}{l}\mathrm{N} \text { of symptoms } \\
\text { Mean (SD) } \\
\text { Median (IQR) }\end{array}$ & $\begin{array}{c}7.3(3.1) \\
7(5-9)\end{array}$ & $\begin{array}{c}6.6(3.3) \\
7(4-9)\end{array}$ & $\begin{array}{c}7.0(3.1) \\
7(5-9)\end{array}$ & $\begin{array}{l}6.8(3.2) \\
9(7-11)\end{array}$ \\
\hline
\end{tabular}

(Continued) 
Table I (Continued).

\begin{tabular}{|c|c|c|c|c|}
\hline \multirow{2}{*}{} & \multicolumn{2}{|c|}{ Participants at Enrollment } & \multicolumn{2}{c|}{ Participants with Follow-Up Around Day 30 } \\
\cline { 2 - 5 } & $\begin{array}{c}\text { Taking Medications } \\
\text { for Autoimmune } \\
\text { Disease }\end{array}$ & $\begin{array}{c}\text { Not Taking Medications } \\
\text { for Autoimmune } \\
\text { Disease }\end{array}$ & $\begin{array}{c}\text { Taking Medications } \\
\text { for Autoimmune } \\
\text { Disease }\end{array}$ & $\begin{array}{c}\text { Not Taking Medications } \\
\text { for Autoimmune } \\
\text { Disease }\end{array}$ \\
\cline { 2 - 5 } & $(\mathbf{n = 7 0 )}$ & $(\mathbf{n = 1 , 4 4 8 )}$ & $\mathbf{( n = 4 I )}$ & $(\mathbf{n = 9 3 6 )}$ \\
\hline Severity score* & & & $11.8(6.4)$ & $11.3(6.4)$ \\
Mean (SD) & $12.1(6.4)$ & $10.9(6.6)$ & $11(7-17)$ & $16(6-15)$ \\
\hline
\end{tabular}

Notes: *Severity score was calculated as the sum of individual symptom severity across 15 symptoms $(0=$ absent; I=very mild/mild; $2=$ moderate; $3=$ severe $)$. Abbreviations: SD, standard deviation; IQR, interquartile range; BMI, body mass index.

decreased sense of smell or taste at enrollment; among those reporting use of medications for autoimmune disease, a higher proportion reported symptoms at all time points in follow-up, as well as symptoms of greater severity (Figure 1).

Around day 30 (range $=24-45$ days) a higher proportion of participants reporting use of medications for autoimmune disease remained symptomatic compared to all other participants, with $67 \%$ vs $34 \%$ continuing to report fatigue, $40 \%$ vs $19 \%$ reporting nasal congestion, $33 \%$ vs $20 \%$ cough, and $33 \%$ vs $12 \%$ shortness of breath (Figure 1).

The analysis of severity revealed unadjusted OR (95\% CI) of reporting $\geq 7$ symptoms among those taking medications for autoimmune conditions at enrollment compared to all other participants was 1.27 (0.75-2.13). After adjusting for age group, gender, race, ethnicity, education level, BMI, smoking, diagnosis of cardiovascular disease, and use of medications (yes/no) for diabetes, lung disease, and hypertension, the OR (95\% CI) was 1.17 (0.68-2.01). The unadjusted OR $(95 \% \mathrm{CI})$ for having a severity score of $\geq 11$ among those taking medications for autoimmune conditions at enrollment compared to all other participants was $1.41(0.84-2.38)$ and $1.32(0.76-2.29)$ after adjusting for the same set of covariates listed above (Table 2).

Forty-four percent of participants $(\mathrm{n}=977)$ provided a follow-up survey around 30 days after enrollment (median [IQR] time of 30 [28;42] days), with 19\% greater retention among those not taking medications for autoimmune disease ( $44.3 \%$ vs $37.6 \%$, respectively). At day 30 , approximately $85 \%$ of participants using medications for autoimmune diseases reported having at least one symptom and $48.8 \%$ reported experiencing three or more symptoms compared to $57 \%$ and $28.5 \%$, respectively, for all others (Table 3 ).
The unadjusted OR $(95 \% \mathrm{CI})$ for reporting three or more symptoms around day 30 after enrollment for those taking medication for autoimmune conditions was 2.39 (1.27-4.47) compared to all others. The effect size increased to 2.53 (1.21-5.29) after adjusting for age group, gender, race, ethnicity, education level, BMI, smoking, diagnosis of cardiovascular disease, use of medications (yes/no) for diabetes, lung disease, hypertension, and the number of symptoms at enrollment (Table 2). At around 30 days after enrollment, those reporting taking medications for autoimmune disease were also more likely to continue experiencing shortness of breath and fatigue, with an unadjusted OR $(95 \% \mathrm{CI})$ of 2.53 (1.20-5.30) and 3.48 (1.83-6.62), respectively. After adjusting for the potential confounders listed above, the ORs (95\% CI) were 2.66 (1.15-6.18) for shortness of breath and 4.73 (2.17-10.34) for fatigue. Unadjusted ORs for all covariates are presented in the supplementary Table S1.

Other factors associated with more severe COVID-19 presentation at enrollment included female gender, smoking, obesity, fewer years of education, and lung disease requiring prescription medications. Individuals in older age groups and racial and ethnic minorities did not appear to be at elevated risk of more severe disease presentation, unlike previously published findings. ${ }^{11}$ However, older age did appear to be associated with symptom persistence, in particular fatigue. Having more symptoms during acute disease was also associated with elevated risk of symptom persistence, which has been previously documented. ${ }^{12}$

\section{Discussion}

An attractive feature of this community-based registry is the diversity of its participants, which include various races and ethnicities, ages, and people with personal habits such as smoking that put them at higher risk of severe consequences 


\begin{tabular}{lccccc|} 
A & \multicolumn{7}{c}{ Days } \\
Symptom & 0 & 7 & 14 & 21 & 30 \\
\hline Fatigue & 84 & 73 & 61 & 60 & 67 \\
\hline Headache & 73 & 61 & 43 & 31 & 26 \\
\hline Cough & 71 & 56 & 37 & 22 & 33 \\
\hline Nasal Congestion & 67 & 53 & 41 & 27 & 40 \\
\hline Aches and Pains & 57 & 39 & 24 & 29 & 29 \\
\hline Decreased Sense of Smell & 56 & 44 & 31 & 27 & 26 \\
\hline Decreased Sense of Taste & 51 & 41 & 28 & 24 & 19 \\
\hline Runny Nose & 46 & 20 & 22 & 16 & 26 \\
\hline Sore Throat & 44 & 15 & 7 & 9 & 14 \\
Shortness of Breath & 43 & 36 & 30 & 13 & 33 \\
\hline Diarrhea & 41 & 17 & 11 & 7 & 10 \\
Chills & 38 & 7 & 9 & 4 & 7 \\
Nausea & 36 & 15 & 13 & 11 & 10 \\
Fever & 26 & 8 & 4 & 4 & 5 \\
Vomiting & 7 & 0 & 2 & 0 & 0 \\
\hline
\end{tabular}

B

Symptom

Fatigue

Headache

Cough

Nasal Congestion

Aches and Pains

Decreased Sense of Smell

Decreased Sense of Taste

Runny Nose

Sore Throat

Shortness of Breath

Diarrhea

Chills

Nausea

Fever

Vomiting

\begin{tabular}{ccccc}
\multicolumn{5}{c}{ Days } \\
0 & 7 & 14 & 21 & 30 \\
\hline 75 & 52 & 45 & 37 & 34 \\
67 & 36 & 29 & 23 & 22 \\
61 & 40 & 30 & 24 & 20 \\
65 & 41 & 27 & 24 & 19 \\
54 & 23 & 18 & 18 & 16 \\
56 & 45 & 36 & 30 & 26 \\
51 & 40 & 29 & 24 & 20 \\
40 & 17 & 14 & 11 & 10 \\
36 & 12 & 7 & 6 & 6 \\
31 & 20 & 15 & 12 & 12 \\
32 & 13 & 6 & 6 & 5 \\
34 & 6 & 3 & 3 & 3 \\
26 & 12 & 7 & 4 & 6 \\
30 & 6 & 2 & 2 & 2 \\
6 & 2 & 2 & 1 & 1
\end{tabular}

D

\begin{tabular}{lccccc} 
Symptom & 0 & 7 & 14 & 21 & 30 \\
\hline Fatigue & 43 & 28 & 20 & 17 & 16 \\
Decreased Sense of Smell & 45 & 30 & 21 & 15 & 11 \\
Aches and Pains & 30 & 11 & 9 & 8 & 8 \\
Headache & 35 & 16 & 12 & 10 & 9 \\
Decreased Sense of Taste & 39 & 23 & 15 & 9 & 7 \\
Nasal Congestion & 32 & 14 & 7 & 7 & 5 \\
Cough & 19 & 11 & 7 & 5 & 5 \\
Diarrhea & 14 & 5 & 3 & 3 & 3 \\
Sore Throat & 12 & 4 & 2 & 3 & 2 \\
Shortness of Breath & 11 & 7 & 4 & 4 & 3 \\
Nausea & 11 & 5 & 2 & 2 & 2 \\
Runny Nose & 14 & 5 & 3 & 3 & 2 \\
Chills & 11 & 2 & 1 & 1 & 1 \\
Fever & 8 & 1 & 1 & 1 & 1 \\
Vomiting & 2 & 1 & 1 & 1 & 1
\end{tabular}

Figure I Symptom prevalence (\%) for COVID-19-positive participants by self-reported use of medication for autoimmune disease.

Notes: (A) Prevalence (\%) of any symptom; taking medication for autoimmune disease at enrollment. (B) Prevalence (\%) of any symptom; not taking medication for autoimmune disease at enrollment. (C) Prevalence (\%) of moderate or severe symptoms; taking medication for autoimmune disease at enrollment. (D) Prevalence (\%) of moderate or severe symptoms; not taking medication for autoimmune disease at enrollment. Data cut as of March I, 202I. Sample size: taking medication for autoimmune disease: day $0: n=70$; day $7: n=59$; day $14: n=54$; day $21: n=45$; day $30: n=42$. Not taking medication for autoimmune disease: day $0: n=I, 448$; day 7: $n=I, 199$; day $14: n=I, 043$; day $21: n=945$; day $30: n=951$. Survey windows: $0=$ enrollment; $7=$ days $3-10 ; 14=$ days $11-17 ; 21=$ days $18-24 ; 30=$ days $25-45$.

of PASC. Although this is a sample of convenience, volunteers include people who are underrepresented in randomized clinical trials, and who may have been reluctant to present for medical care during the pandemic. This community-based study thus offers insights into COVID populations that have been poorly characterized to date.

While symptoms reported to an on-line registry without the intervention of a clinician may be less dependable, the symptoms reported herein were described in terms readily understandable to most consumers, especially the relatively well-educated participants in this registry. Furthermore, the ability of consumers to accurately selfreport their medication use has been validated in a multicountry European study of pregnant women. ${ }^{13}$ For COVID-19, factors associated with more severe disease presentation at enrollment are plausible, including female 


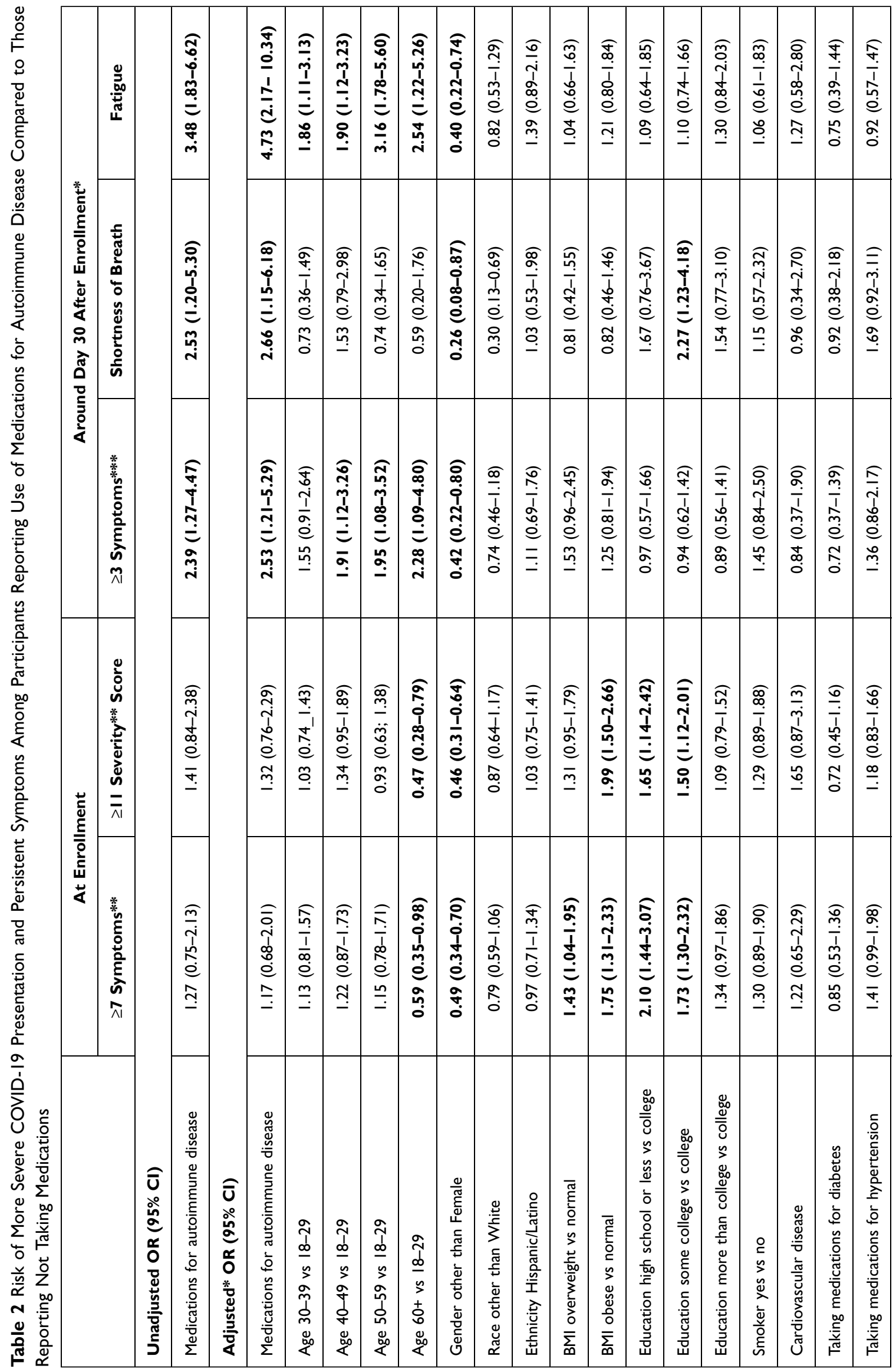




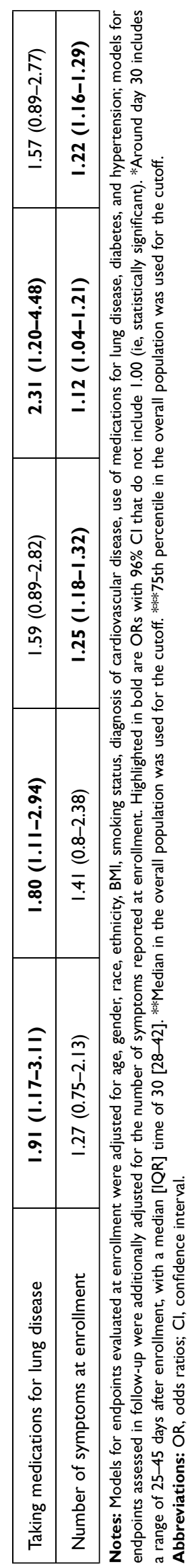

gender, smoking, obesity, and lung disease requiring medications.

Also worth noting is that registry participants who completed follow-up around day 30 were slightly older and had more education. Users of medication for autoimmune disease who had other risk factors such as obesity, lung disease, or hypertension were slightly less likely to complete follow-up around 30 days than those with similar risk factors who reported not taking medications for autoimmune disease. This suggests that our effect estimates may be underestimating the additional risk for users of medication for autoimmune disease. Although payment of a modest incentive increased the likelihood of completing a survey around day 30, there was not a large retention difference by incentive status between users and non-users of medications for autoimmune conditions. Incentive receipt is considered unlikely to have introduced bias.

After adjustment for age group, gender, race, ethnicity, smoking, and comorbidities, it appears that people who report taking medications for autoimmune disease in our study are i) $30 \%$ more likely to have more severe presentations of COVID-19 during the acute phase, ii) 2.5-times more likely to continue experiencing three or more symptoms 30 days post-acute illness, and iii) more than twice as likely to report persistent debilitating symptoms of COVID-19, such as shortness of breath and fatigue, than other participants in the study. Although the CIs are quite wide, likely due in large part to the relatively small sample size, the central tendencies of these effect estimates indicate an increased risk, further supported by lower limits of the $95 \%$ confidence limits that exceed the null. In addition, studies of immune-suppressed or dysregulated populations, such as those with solid-organ transplants or cancer, also point to elevated risk for severe disease. ${ }^{14-16}$ As an example, a small study of 62 patients with rheumatic and musculoskeletal disease suggested more severe disease presentation in users of corticosteroids. ${ }^{17}$

Explanations for our findings remain speculative but would include the immune dysregulation inherent in autoimmune disease patients being associated with persistent but inappropriate inflammation, incomplete viral clearance, or occult reproduction, occasioned by the autoimmune disorder itself or the prescribed medication. Interestingly, there appeared to be no difference for the hallmark symptoms of anosmia and ageusia, which might argue against persisting viral reproduction. ${ }^{18}$ 
Table 3 Distribution of Symptoms at Enrollment and Follow-Up by Use of Medications for Autoimmune Disease

\begin{tabular}{|c|c|c|c|c|}
\hline & \multicolumn{2}{|c|}{ Participants at Enrollment } & \multicolumn{2}{|c|}{$\begin{array}{l}\text { Participants with Follow-Up Around Day } \\
\qquad 30\end{array}$} \\
\hline & $\begin{array}{c}\text { Taking } \\
\text { Medications for } \\
\text { Autoimmune } \\
\text { Disease }\end{array}$ & $\begin{array}{l}\text { Not Taking } \\
\text { Medications for } \\
\text { Autoimmune } \\
\text { Disease }\end{array}$ & $\begin{array}{c}\text { Taking } \\
\text { Medications for } \\
\text { Autoimmune } \\
\text { Disease }\end{array}$ & $\begin{array}{l}\text { Not Taking } \\
\text { Medications for } \\
\text { Autoimmune } \\
\text { Disease }\end{array}$ \\
\hline & $(n=70)$ & $(n=I, 448)$ & $(n=4 I)$ & $(n=936)$ \\
\hline Analysis endpoints & $\mathrm{n}(\%)$ & $\mathrm{n}(\%)$ & $\mathrm{n}(\%)$ & $\mathrm{n}(\%)$ \\
\hline$\geq 7$ symptoms at enrollment & $41(58.6)$ & $739(51.0)$ & $\mathrm{n} / \mathrm{a}$ & $\mathrm{n} / \mathrm{a}$ \\
\hline$\geq I$ I severity score at enrollment & $40(57.1)$ & $708(48.9)$ & $\mathrm{n} / \mathrm{a}$ & $\mathrm{n} / \mathrm{a}$ \\
\hline$\geq 1$ symptom at follow-up around day 30 & $\mathrm{n} / \mathrm{a}$ & $\mathrm{n} / \mathrm{a}$ & $35(85.4)$ & $533(56.9)$ \\
\hline$\geq 3$ symptoms at follow-up around day 30 & $\mathrm{n} / \mathrm{a}$ & $\mathrm{n} / \mathrm{a}$ & $20(48.8)$ & $267(28.5)$ \\
\hline Shortness of Breath & $30(42.9)$ & $443(30.6)$ & $10(24.4)$ & $106(11.3)$ \\
\hline Fatigue & $59(84.3)$ & I,092 (75.4) & $25(61.0)$ & $290(31.0)$ \\
\hline
\end{tabular}

Abbreviations: SD, standard deviation; IQR, interquartile range.

These findings resonate with an earlier study of rheumatoid arthritis and influenza, which found an increased incidence of influenza and of influenza complications in rheumatoid patients, with women again appearing at greater risk; adjustment for type of autoimmune medication did not impact these risks, suggesting that underlying autoimmune disease itself could be to blame. ${ }^{19}$ This may hold implications for the timing of dexamethasone, immune modulators such as tocilizumab, and antiviral initiation in the management of COVID-19. ${ }^{20,21}$

\section{Conclusions}

While understanding the pathogeneses of PASC might inform overall COVID-19 management and suggest new interventions and targets, the immediate priority would be to recognize this group of patients as being particularly vulnerable, and to investigate whether aggressive early intervention, such as antibody cocktails and antivirals, might reduce disease severity and the incidence of PASC, with both individual and societal benefit.

\section{Abbreviations}

BMI, body mass index $\left(\mathrm{kg} / \mathrm{m}^{2}\right)$; CARE, COVID-19 Active Research Experience; CI, confidence interval; COVID-19, Coronavirus Disease 2019; IQR, interquartile range; PAS, Post-Authorization Safety; PASC, Post-Acute Sequelae of COVID-19; USD, United Stated Dollars; OR, odds ratios.

\section{Data Sharing Statement}

Due to data privacy and security regulations the researchers are not able to share participant level data.

\section{Ethics Approval and Informed Consent}

This study was approved by Advarra Institutional Review Board and the main protocol is registered at Clinicaltrials. gov (NCT04368065.) All participants provided informed consent online.

\section{Consent for Publication}

Consent from participants for publication of research finding was provided online.

\section{Funding}

No external funding was received for this study.

\section{Disclosure}

The authors have no competing interests to disclose.

\section{References}

1. Yelin D, Margalit I, Yahav D, Runold M, Bruchfeld J. Long COVID19-it's not over until? Clin Microbiol Infect. 2020;S1198-743X(20) 30750-3.

2. Baang JH, Smith C, Mirabelli C, et al. Prolonged severe acute respiratory syndrome coronavirus 2 replication in an immunocompromised patient. J Infect Dis. 2021;223(1):23-27. doi:10.1093/ infdis/jiaa666

3. Liu Y, Sawalha AH, Lu Q. COVID-19 and autoimmune diseases. Curr Opin Rheumatol. 2021;33(2):155-162. doi:10.1097/BOR.00000000 00000776

4. Dreyer NA, Reynolds M, Mack CD, et al. Self-reported symptoms from exposure to COVID-19 provide support to clinical diagnosis, triage and prognosis: an exploratory analysis. Travel Med Infect Dis. 2020;38:101909. doi:10.1016/j.tmaid.20 20.101909 
5. U.S. Department of Health and Human Services, Food and Drug Administration. Assessing COVID-19-related symptoms in outpatient adults and adolescent subjects in clinical trials of drugs and biological products for COVID-19 treatment and prevention. Guidance for industry; September 2020. Available from: https://www.fda.gov/ media/142143/download. Accessed March 23, 2021.

6. Huang C, Huang L, Wang Y, et al. Six-month consequences of COVID-19 in patients discharged from hospital: a Cohort Study. Lancet. 2021;397 (10270):220-232. doi:10.1016/S0140-6736(20)32656-8

7. El Sayed S, Shokry D, Gomaa SM. Post-COVID-19 fatigue and anhedonia: a Cross-Sectional Study and their correlation to post-recovery period. Neuropsychopharmacol Rep. 2021;41 (1):50-55. doi:10.1002/npr2.12154

8. Venkatesan P. NICE guideline on long COVID. Lancet Respir Med. 2021;9(2):129. doi:10.1016/S2213-2600(21)00031-X

9. van der Sar-van der Brugge S, Talman S, Boonman-de Winter L, et al. Pulmonary function and health-related quality of life after COVID-19 pneumonia. Respir Med. 2021;176:106272. doi:10.1016/ j.rmed.2020.106272

10. Cortés-Telles A, López-Romero S, Figueroa-Hurtado E, et al. Pulmonary function and functional capacity in COVID-19 survivors with persistent dyspnea. Respir Physiol Neurobiol. 2021;288:103644. doi:10.1016/j.resp.2021.103644

11. Rashedi J, Mahdavi Poor B, Asgharzadeh V, et al. Risk factors for COVID-19. Infez Med. 2020;28(4):469-474.

12. Sudre CH, Murray B, Varsavsky T, et al. Attributes and predictors of long COVID. Nat Med. 2021;27(4):626-631. doi:10.1038/s41591021-01292-y

13. Dreyer NA, Blackburn SCF, Mt-Isa S, et al. Direct-to-patient research: piloting a new approach to understanding drug safety during pregnancy. JMIR Public Health Surveill. 2015;1(2):e22. doi:10.2196/publichealth.4939

14. Fung M, Babik JM. COVID-19 in immunocompromised hosts: what we know so far. Clin Infect Dis. 2020;72:ciaa863.
15. Dai M, Liu D, Liu M, et al. Patients with cancer appear more vulnerable to SARS-CoV-2: a Multicenter Study during the COVID-19 outbreak. Cancer Discov. 2020;10(6):783-791. doi:10.1158/2159-8290.CD-20-0422

16. Kuderer NM, Choueiri TK, Shah DP, et al. Clinical impact of COVID-19 on patients with cancer (CCC19): a Cohort Study [published correction appears in Lancet. 2020 Sep 12;396(10253):758]. Lancet. 2020;395(10241):1907-1918. doi:10.1016/S0140-6736(20) 31187-9

17. Montero F, Martínez-Barrio J, Serrano-Benavente B, et al. Coronavirus disease 2019 (COVID-19) in autoimmune and inflammatory conditions: clinical characteristics of poor outcomes. Rheumatol Int. 2020;40(10):1593-1598. doi:10.1007/s00296-02004676-4

18. Scoppettuolo P, Borrelli S, Naeije G. Neurological involvement in SARS-CoV-2 infection: a clinical systematic review. Brain Behav Immun Health. 2020;5:100094. doi:10.1016/j.bbih.2020. 100094

19. Blumentals WA, Arreglado A, Napalkov P, Toovey S. Rheumatoid arthritis and the incidence of influenza and influenza-related complications: a Retrospective Cohort Study. BMC Musculoskelet Disord. 2012;27(13):158. doi:10.1186/14712474-13-158

20. Alhazzani W, Evans L, Alshamsi F, et al. Surviving sepsis campaign guidelines on the management of adults with coronavirus disease 2019 (COVID-19) in the ICU: first update. Crit Care Med. 2021;49(3):e219-e234. doi:10.1097/CCM.000000000 0004899

21. Snow TAC, Saleem N, Ambler G, Nastouli E, Singer M, Arulkumaran N. Tocilizumab in COVID-19: a meta-analysis, trial sequential analysis, and meta-regression of randomized-controlled trials. Intensive Care Med. 2021;21:1-12.
International Journal of General Medicine

\section{Publish your work in this journal}

The International Journal of General Medicine is an international, peer-reviewed open-access journal that focuses on general and internal medicine, pathogenesis, epidemiology, diagnosis, monitoring and treatment protocols. The journal is characterized by the rapid reporting of reviews, original research and clinical studies across all disease areas. The manuscript management system is completely online and includes a very quick and fair peer-review system, which is all easy to use. Visit http://www.dovepress.com/ testimonials.php to read real quotes from published authors. 